\title{
Renewable Energy Consumption, Environmental Sustainability, and Economic Growth in Developing Countries
}

\author{
Tonuchi, E. Joseph ${ }^{1}$ \\ Ariolu, C. Charles ${ }^{2}$ (D)
}

'Department of Statistics, Central Bank of Nigeria, Abuja; Department of Economics, University of Nigeria, Nsukka, Nigeria.

Email: tonuchijoseph@gmail.com Tel: +234-7069321463

Department of Statistics, Central Bank of Nigeria, Abuja, Nigeria.

Email:charlesariolu@ymail.com Tel: +234-8185726850

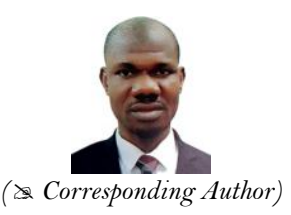

\begin{abstract}
This study investigated the nexus between renewable energy consumption and economic growth in developing countries and the role of environmental sustainability in the nexus between renewable energy consumption and economic growth. To achieve the objective, the researcher employed General Method of Moment (GMM) to solve for the possible problem of endogeneity common in previous studies using data sourced from World Bank. It was discovered that renewable energy consumption has positive but weak impact on economic growth in developing countries but when environmental sustainability is accounted, the impact of renewable energy consumption improves. Similarly, interacting $\mathrm{CO} 2$ with renewable energy changes the sign of $\mathrm{CO} 2$ from positive to negative. The implication of this study is that renewable energy consumption impacts on the economy might be weak but is justified giving its environmental sustainability potential.
\end{abstract}

Keywords: Developing countries, Environmental sustainability, Renewable energy, Renewable energy consumption, Renewable energy potential.

JEL Classification: D62; F64; P28; Q2; Q3; Q5.

Citation | Tonuchi, E. Joseph; Ariolu, C. Charles (2021). Renewable Energy Consumption, Environmental Sustainability, and Economic Growth in Developing Countries. Asian Bulletin of Energy Economics and Technology, 6(1): 43-69.

History:

Received: 5 March 2021

Revised: 14 April 2021

Accepted: 17 May 2021

Published: 9 June 2021

Licensed: This work is licensed under a Creative Commons Attribution 3.0 License (c)

Publisher: Asian Online Journal Publishing Group
Acknowledgement: Both authors contributed to the conception and design of the study.

Funding: This study received no specific financial support.

Competing Interests: The authors declare that they have no conflict of interests.

Transparency: The authors confirm that the manuscript is an honest, accurate, and transparent account of the study was reported; that no vital features of the study have been omitted; and that any discrepancies from the features of the study have been omitted;
study as planned have been explained.

Ethical: This study follows all ethical practices during writing.

\section{Contents}

1. Introduction

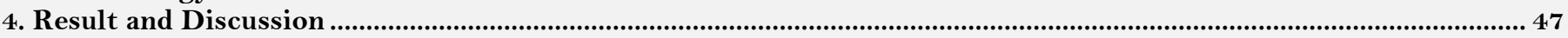

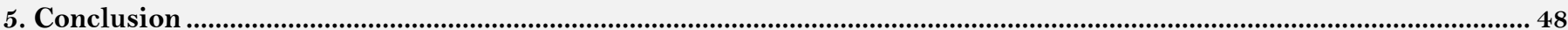

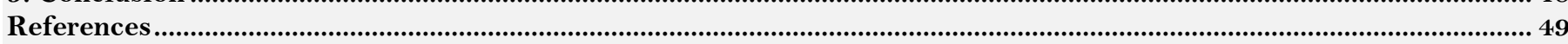




\section{Contribution of this paper to the literature}

The study contributes to the existing literature by investigating the role of environmental sustainability in the nexus between renewable energy consumption and economic growth in developing countries.

\section{Introduction}

\subsection{Background of the Study}

Recent literature on energy has regarded energy as the fifth factor of production simply because of its importance in the processes of production, industrialization, urbanization, transportation, and sustainable economic growth (Oladeji, 2014). There is no gainsaying that no country can realize sustainable economic growth and development without developing its energy/power sectors. In fact, lack of access to energy indicates a deficient situation as regards achieving sustainable economic growth, lowering poverty, and accelerating development in any country of the world.

Tonuchi (2019) has argued that renewable energy is the most significant source of energy in terms of its sustainability, availability, and environmental friendliness. This feature of renewable energy has made it a sortafter form of energy to save the environment from $\mathrm{CO}_{2}$ emissions and other environmental degradation. The argument is that given that the world has the potential to go 100 percent renewable as renewable energy is distributed globally, why hurt the environment cum humanity by investing in non-renewable energy? Similarly, Tafti and Mottaghitalab (2017) noted that given that energy demand across the globe is increasing rapidly, continuous dependence on fossil fuels to meet the global energy need would only hurt the global environment as more $\mathrm{CO}_{2}$ will be emitted into the atmosphere and cause harm to human health.

On the role of energy in economic growth, several researchers have shared their views on this relationship with energy is a relatively new factor and not included in traditional economic growth models (Stern, 2011; Tonuchi, 2019). Most studies have explained economic activity and growth in terms of a production function. Neoclassical growth models usually regard capital, labour, and land as the primary factors of production, while energy is regarded as an intermediate input inadvertently produced by the primary factors of production and subsumed under capital (Dogan, Sebri, \& Turkekul, 2016). This argument has been largely criticized because all production involves the transformation of matter in some ways. Energy, which drives that transformation, is therefore necessary for economic production and economic growth (Stern, 2011).

While some empirical studies find that renewable energy impacts favorably on the economy through positive spillover effects on income (Dogan et al., 2016; Fotourehchi, 2017), others argue that it impacts the economy unfavorably through high energy generation costs and abandonment of conventional energy generation technologies (Can \& Korkmaz, 2018). Similarly, most of the studies focused on the relationship between renewable energy consumption and economic growth (Bozkurt \& Destek, 2015; Marinaş, Dinu, Socol, \& Socol, 2018). Still, they ignored the role of environmental sustainability in such a relationship. Few studies like Jebli and Youssef (2015) and Apergis and Payne (2010) though included a measure of $\mathrm{CO} 2$ in their modeling but never interacted it with renewable energy consumption to see how the model behaves.

Economic literature states that interacting income with price often changes the equation as most consumers with higher income might ignore the price changes. The same applies here as renewable energy might be pursued regardless of its cost and immediate impact on the economy because of its environmental friendliness. Thus, this study aims to determine how introducing environmental sustainability measures impacts the nexus between renewable energy consumption and economic growth in developing countries.

\section{Literature Review}

\subsection{Meaning and Overview of Renewable Energy}

Renewable energy, like most concepts, lacks a universal definition (Tonuchi, 2019), but there are common themes in defining or explaining it. These include the fact that for any energy source to be qualified as renewable, it must have the ability to replenish itself when used, sustainable over a long time, and environmentally friendly. Arvind and Kaushik (2017) defined renewable energy as those forms of energy generated in an environmentally friendly manner and offer the planet a chance to reduce carbon emission while meeting the basic energy needs of humanity. Oladeji (2014) shared a similar stance when the author argued that renewable energy is generated in an environmentally friendly manner, thereby reducing the accumulation of $\mathrm{CO}_{2}$ in the environment.

Renewable energy does not only represent an alternative to fossil fuel. In fact, it is the only option that can guarantee the sustainable development of the economy, ensure humanity's survival, and ultimately ensure the preservation of the climate. Some other definitions of renewable energy see it as that energy derived directly or indirectly from solar energy (Vaselbehagh, Karkhanechi, Takagi, \& Matsuyama, 2017). In a way, almost all the energy we use today, including fossil fuels, can be considered a form of solar energy. Vaselbehagh et al. (2017) admit as much in arguing that the most common forms of energy such as coal, gas, wood, and oil are embodied forms of energy stored and transformed by natural processes. They argued that "climate change due to emissions of greenhouse gases (GHGs) becomes an issue when stored energy is converted to useable forms of energy (heat, electricity, fuels, chemicals) at a rate far exceeding the rate of formation”. For instance, regarding the three major non-renewable energy sources, including coal, natural gas, and fossil fuel, the time it takes between energy formation and human usage is in the range of one to one million. This simply means that the world uses in one year what takes millions of years for nature to process (Zhou, Yang, \& Lu, 2012).

According to IEA (2015), renewable energies are those energy gotten from sources that are replenishable in nature. This definition raised some questions regarding the time lag it takes for energy to replenish. The various forms of energy generated directly from the sun include solar energy, wind energy, biomass, geothermal, solid biomass, biogas, biofuel, and hydropower.

Another dimension to view renewable energy is the degree of flow. It is possible that energy sources can be replenished from time to time, but is the flow of the energy constant over time? This question led to another dimension of renewable energy definitions by various scholars. Zhou et al. (2012) noted that renewable energy is inexhaustible but is limited inflow; that is, the amount of energy available at each point in time is limited. This 
explains why most energy scholars have started advocating a hybrid renewable energy technology that combines the various forms of renewable energies to generate power over time. From the above definitions and meanings of renewable energy, it is possible to conclude that renewable energy are those forms of energy that are inexhaustible, replenishable in nature, and generate less degree of $\mathrm{CO}_{2}$ emission when used by humans. If we consider this to be a good understanding of renewable energy, then one can see non-renewable energy as those energies that store with zero or a minute rate of replenishment relative to its human usage over time.

Vaselbehagh et al. (2017) argue that only biomass renewable energy has an ideal ratio between human usage and the natural processing time of all the stored renewable energy sources. The above assertion suffices that renewable energy entails those energy used by humans and replenishes in a time scale that is much equivalent to human lifetimes. This definition clearly revealed the importance of renewable energy towards achieving a cleaner environment and mitigating the problem of climate change worldwide.

\subsection{Theoretical Foundation}

The theoretical foundation of this study is based on the Environmental Kuznets Curve theory which argued that as nations increases in their economic activities, they tend to generate environmental degradation up to a point when further rise in economic growth induces a reduction in environmental degradation. Researchers hypothesize that at a point, higher levels of income may reduce environmental degradation (Kisswani, Harraf, \& Kisswani, 2018). The Environmental Kuznets Curve (EKC, hereafter) is an important area in the field of environmental economics. The EKC hypothesis looks at the relationship between economic growth and the environment. This relation (per-capita income vs. per-capita index of environmental degradation) is supposed to take the form of an inverted U-shaped curve, which means that environmental degradation rises at an initial level of economic growth till a certain point (i.e., turning point), and it turns to fall at a higher level of economic growth (Anastacio, 2017).

While Kuznet (1955) introduced a curve to show the relationship between economic growth and income inequality nonetheless, the $\mathrm{EKC}$, since then, became a valuable area of applied research in environmental economics. Grossman and Helpman (1991) cited in Anastacio (2017) introduced the first EKC analysis. In studying the relationship between per capita income and various environmental indicators, their pioneering research offered empirical evidence about the inverted U-shaped curve of the relationship between environmental degradation and economic growth.

To date, a number of empirical papers have explored the EKC hypothesis as attempt to examine the adverse effect of climate change and global warming on the economy. The EKC hypothesis has long been a controversial issue in the latest economic literature as the overall impact of income growth on the environment remains ambiguous (see, for example, Cole (2004); Stern (2011) and Dinda (2004)) reviewed the literature that explored the inverted U-shaped relationship and surveyed the empirical studies that examined the nexus between economic growth and emissions. Both studies indicate that the findings were inconclusive. But this is totally different from the findings of Apergis and Payne (2010) who discovered that the inverted U-shape with growth is significant. Atems and Hotaling (2018) find a negative relationship between the inverted U-shape with growth.

\subsection{Empirical Literature}

There is generally no consensus in the literature as regards the link between renewable energy consumption and economic growth because the structural features of the analyzed countries, their development stage, econometric methods used, and time frame analyzed are different. However, some researchers argue that the relationship between renewable energy consumption and economic growth are neutral, meaning that there is no evidence renewable energy has significant impact on growth (Aslan, 2013; Bozkurt \& Destek, 2015; Dogan et al., 2016; Inglesi-Lotz, 2016). They identify two possibilities: real GDP driven by service sector, and policies that seek to reduce energy consumption to decrease greenhouse gas pollution effects. In line with the above, some authors have found an inverse relationship between renewable energy consumption and economic growth, and environmental sustainability. Among such, Tafti and Mottaghitalab (2017) argue that lowering energy consumption boosts the domestic output if an economy is based to a greater extent on the service sector, which is less energy-consuming.

On the other hand, other studies found a positive relationship between renewable energy consumption and economic growth (Apergis \& Payne, 2010; Dogan et al., 2016; Jebli \& Youssef, 2015). The argument is that renewable energy consumption drives economic activities which ultimately lead to growth.

Most empirical studies in European countries or OECD support a positive link between renewable energy consumption and economic growth or environmental sustainability (Ibrahim, Sulaiman, \& Abdul-Rahim, 2019; Lee, 2019; Marinaş et al., 2018). For instance, Lee (2019) find enough evidence to support a link between renewable energy consumption, economic growth, industrialization, and $\mathrm{CO}_{2}$ emissions in the long-run and short-run. The study notes that while renewable energy consumption has been increasing with growth, $\mathrm{CO}_{2}$ emissions have been declining in the region. However, the result also suggests that both economic growth and industrialization have been achieved at the cost of harming the environment. The increased consumption of renewable energy tends to play an important role in curbing carbon emissions in the region.

Similarly, Tafti and Mottaghitalab (2017) investigate the impact of renewable energy consumption on the economic growth of OPEC members between 2012 and 2016. As expected, it reveals that renewable energy consumption has significant positive impact on economic growth among OPEC countries. It further finds that there exists a bidirectional relationship between economic growth and renewable energy consumption.

In attempt to mitigate the methodological issues with previous studies, Atems and Hotaling (2018) employed a General Method of Moment to estimate the impact of renewable and non-renewable electricity generation on economic growth in 174 countries. The study demonstrates that both renewable and non-renewable energy consumption have a positive significant impact on economic growth, but the former appears to have a stronger positive impact on economic growth.

Most econometric studies document a bi-directional relationship between renewable energy and economic growth on the direction of causality between renewable energy consumption and economic growth. For instance, 
Marinaş et al. (2018) using ARDL estimation techniques to investigate the causal relationship between renewable energy consumption and economic growth, discover that economic growth and renewable energy consumption are independent of each other and that in the long-run both has directional relationship. Tafti and Mottaghitalab (2017) also agree.

While most studies have investigated renewable energy consumption and economic growth, not many have examined the moderating role of environmental degradation in the nexus between renewable energy consumption and economic growth which, as stated earlier, is the focus of this piece. Also, most of the previous studies suffer either endogeneity issues of static models by using DOLS, OLS, fixed effect, and random effect to estimate the panel (Marinaş et al., 2018). Others that use VECM and ECM to estimate the impact of renewable energy consumption on economic growth suffer endogeneity peculiar with growth equations and the weak parameter estimating power because of the small sample size (Lee, 2019).

This study argues that renewable energy impacts on economic growth across countries cannot be fully ascertained without accounting for the role of environmental sustainability policies and indices. Just as the relationship between demand and price cannot be fully concluded for an individual without factoring in income, so also with renewable energy consumption and economic growth nexus. It cannot be completed without factoring in environmental sustainability. To remedy the issues with previous studies, this study employs dynamic General Method of Moment (GMM) to overcome the endogeneity issues peculiar with previous studies and deal with omitted variables peculiar with most growth studies. GMM could incorporate dummy variables that serve as an instrument for the omitted variables, thus making the parameter estimates more reliable and trusted.

\section{Methodology}

\subsection{Data and Sources}

The data for this study was sourced from World Bank Development (WDI) indicators 2019. The data consist of 54 developing countries selected across the region for a period of 18 years (2001-2019).

\subsection{Model Specification}

To check if there is any significant relationship between renewable energy consumption and growth in income per capita across the world, the study employed the simple Cobb-Douglas production function to capture the relationship as in Equation 1;

$$
Y_{i, t}=K_{i, t}^{\alpha} L_{i, t}^{\eta} \operatorname{Access}_{i, t}^{\rho} R E n_{i, t}^{\theta} \varepsilon_{i, t}
$$

where; $\mathrm{Y}=$ growth rate of income per capita,

$\mathrm{K}=$ Stock of physical capital,

$\mathrm{L}=$ labour force employed at age 15 and above,

Access = Percentage of population with access to electricity,

$\mathrm{REn}=$ Renewable energy consumption and,

$\varepsilon$ is the error term.

To make Equation 1 linear, we can take the natural log.

$\ln y_{i, t}-\ln y_{0}=\alpha\left(\ln K_{i, t}-\ln K_{0}\right)+\eta\left(\ln L_{i, t}-\ln L_{0}\right)+\rho\left(\ln A_{i, t}-\ln A_{0}\right)+\theta\left(\ln E n_{i, t}-\ln R E n_{0}\right)+\left(\varepsilon_{i, t}-\ln \varepsilon_{0}\right)$ (2)

We can take the first difference of Equation 2 as is re-written in Equation 3

$$
\Delta \ln y_{i, t}=\alpha \Delta \ln K_{i, t}+\eta \Delta \ln L_{i, t}+\rho \Delta \ln \operatorname{Access}_{i, t}+\theta \Delta \ln R E n_{i, t}+\Delta \varepsilon_{i, t}
$$

To resolve possible endogeneity issue, the researchers included the lag of the dependent variable among the covariate to account for the problem of simultaneity bias mostly resulting from omitted variables. Since the unobserved often appears after a period lag in the output, one lagged period was used. We also introduce renewable energy consumption at level, since most empirical literature using renewable at difference founds it insignificant. $\Delta \operatorname{lny}_{i, t}=\beta_{0}+\beta_{1} \operatorname{lnAccess}_{i, t}+\beta_{2} \Delta \ln K_{i, t}+\beta_{3} \Delta \ln L_{i, t}+\beta_{4} \Delta \ln R E n_{i, t}+\beta_{5} \ln R E n_{i, t}+\beta_{6} \ln y_{i, t-1}+\lambda_{i}+\Delta \varepsilon_{i, t}$ (4) where $\lambda_{i}$ represents the countries specific features. One of the common arguments favoring shifting energy consumption to renewable is that it guarantees a more sustainable environment as it emits less $\mathrm{CO}_{2}$ to the atmosphere. To this end, we modified Equation 4 above to capture the moderating role of $\mathrm{CO}_{2}$ on the nexus between economic growth and renewable energy consumption across countries. This is Equation 5 .

$\Delta \operatorname{lny}_{i, t}=\beta_{0}+\beta_{1} \operatorname{lnAccess}_{i, t}+\beta_{2} \Delta \ln K_{i, t}+\beta_{3} \Delta \ln L_{i, t}+\beta_{4} \Delta \operatorname{lnREn_{i,t}}+\beta_{5} \operatorname{lnREn}_{i, t}+\beta_{6} \operatorname{lnCO2}_{i, t}+\beta_{7} \operatorname{lnREn_{i,t}} *$ $\operatorname{lnC} 02_{i, t} \beta_{8} \operatorname{lny}_{i, t-1}+\lambda_{i}+\Delta \varepsilon_{i, t}(5)$

Where $\beta_{7}$ is the parameter estimate of the moderating factors between renewable energy and economic growth nexus. The parameter estimate of the moderating factors is expected to negatively affect economic growth since more investment in renewable energy to protect the environment will induce $\mathrm{CO}_{2}$ emission to decline. To check if Kuznet curve prediction hold in our model, we also introduce the square of $\mathrm{CO}_{2}$ in Equation 6. Kuznet curve states that as countries grow, the $\mathrm{CO}_{2}$ emission will initially rise until it starts falling when the countries start adopting more environmentally friendly energy and equipment.

$\Delta \ln y_{i, t}=\beta_{0}+\beta_{1} \operatorname{lnAccess}_{i, t}+\beta_{2} \Delta \ln K_{i, t}+\beta_{3} \Delta \ln L_{i, t}+\beta_{4} \Delta \operatorname{lnREn_{i,t}}+\beta_{5} \operatorname{lnREn_{i,t}}+\beta_{6} \operatorname{lnCO2} 2_{i, t}+\beta_{7} \operatorname{CO2}_{i, t}^{2}+$ $\beta_{8} \ln y_{i, t-1}+\lambda_{i}+\Delta \varepsilon_{i, t}(6)$

To solve some specific econometric issues peculiar to other previous empirical studies, the study employed System General Method of Moment (GMM) to estimate the models. GMM is an econometric method that integrates information from both the observed time series and the population moment conditions to generate parameter estimates. It uses the first four population moments; mean, variance, skewness and kurtosis to generate the estimates. The dynamic GMM framework of Equation 4-6 can be re-specified in its GMM form as in Equation 7 ;

$$
y_{i t}=\alpha+\gamma_{1} \ln y_{i t-1}+\beta^{\prime}[X]_{i t}+\lambda_{i}+\varepsilon_{i t}
$$

Where; $y_{i t}$ is the growth rate of income per capita (used to capture economic growth) as the dependent variable and $\ln y_{i t-1}$ is the endogenous variable meant to solve the endogeneity issues common in growth equation, and $X_{i t}$ 
is the vector of exogenous variables including renewable energy consumption and the $\mathrm{CO}_{2}$ emission (moderating variables), $\varepsilon_{i t}$ error term that has constant mean, $\mathrm{E}\left[\varepsilon_{i t}\right]=0$. Other variables remain as defined earlier. And $\mathrm{i}=$ $1 \ldots \ldots . \mathrm{N}$., and $\mathrm{t}=2, \ldots \ldots, \mathrm{T}$., also, $\left[\lambda_{i}+\varepsilon_{i t}\right]$ is the standard error component. We assume that, $\mathrm{E}\left[\lambda_{i}\right]=\mathrm{E}\left[\varepsilon_{i t}\right]$ $=\mathrm{E}\left[\lambda_{i}+\varepsilon_{i t}\right]=0$. System GMM is chosen over difference GMM in our case because of possible downward bias resulting from weak instrument in difference GMM. Notice that if we take the first difference of Equation 7 we obtain Equation 8:

$$
\Delta y_{i t}=\alpha+\gamma_{1} \Delta \ln y_{i t-1}+\beta^{\prime}[X]_{i t}+\lambda_{i}+\Delta \varepsilon_{i t}
$$

From equation 8 , lagged dependent variable $\Delta y_{i t}$ has a correlation with the error term $\Delta \varepsilon_{i t}$ This implies that there is a potential endogenous problem that may render parameter estimates from equation 8 inconsistent. As such, the first difference instrument cannot sufficiently be used to address potential issues in the model and generate downward bias (Bond, Hoeffler, \& Temple, 2001). Therefore, a system GMM becomes the only option to address the potential endogeneity problem in the equation.

\section{Result and Discussion}

This section presents and discusses the results from the data. The study started by conducting a correlation matrix as presented in Table 1. Given that some models have close to seven exogenous variables, it becomes important to check the presence or absence of multicollinearity in the model to avoid the incidence of perfect correlation among covariates. As seen in Table 1, there is no evidence of multicollinearity in the series as none have more than 60 percent correlation.

Table-1. Correlation Matrix.

\begin{tabular}{|c|c|c|c|c|c|c|c|}
\hline Variables & $\bar{y}$ & $\bar{K}$ & $\mathbf{L}$ & Access & Ren & $\mathrm{CO} 2$ & $\mathrm{CO}^{2}{ }^{2}$ \\
\hline $\mathrm{y}$ & 1 & & & & & & \\
\hline $\mathrm{K}$ & $0.587^{* * * *}$ & 1 & & & & & \\
\hline $\mathrm{L}$ & $0.606^{* * * *}$ & $0.481^{* * * *}$ & 1 & & & & \\
\hline Access & $0.275^{* * * *}$ & $0.290^{* * * *}$ & -0.0552 & 1 & & & \\
\hline Ren & $0.3897^{* *}$ & $0.0858^{*}$ & $-0.164^{* * * *}$ & $0.365^{* * * *}$ & 1 & & \\
\hline $\mathrm{CO} 2$ & $0.387^{* * * * * *}$ & $0.270^{* * * *}$ & $-0.181^{* * *}$ & $-0.106^{* * *}$ & -0.3339 & 1 & \\
\hline $\mathrm{CO} 2^{2}$ & $0.128^{* * * * *}$ & 0.04185 & -0.0661 & $0.268^{* * * *}$ & $-0.308^{* * * *}$ & 0.00613 & 1 \\
\hline
\end{tabular}

To ensure the reliability of estimate in policy discussion, the researchers further made effort to subject the data to stationarity test. While literature argues that there is virtually no need for unit root test in a strong balances panel data especially where N>T (Im, Pesaran, \& Shin, 2003) the study however proceeds to subject the data to a unit root test to clear all possible doubt on the data using the first generation unit root tests. The Im, Pesaran \& Shin (IPS) and Fisher based approaches were employed to check for stationarity.

Table-2. Panel Unit Root test Using IPS and Fisher Approach/ AIC Criteria.

\begin{tabular}{c|c|c|c|c}
\multicolumn{5}{c}{ Table-2. Panel Unit Root test Using IPS and Fisher Approach/ AIC Criteria. } \\
\hline & IPS @ Level & IPS @ First Diff. & Fisher @ Level & Fisher @ First Diff. \\
\cline { 5 - 6 } & Statistics/P-value & Statistics/P-value & Statistic/ P-value & Statistics/ P-value \\
\hline Lny & $3.472484(1.0000)$ & $-9.1634(0.0000)^{* * *}$ & $-2.7720(0.6995)$ & $-13.6832(0.0000)^{* * *}$ \\
\hline LnK & $6.264739(1.0000)$ & $-5.0837(0.00003)^{* * *}$ & $3.7828(1.0000)$ & $-6.9801(0.0000)^{* * *}$ \\
\hline LnL & $4.264733(0.9874)$ & $-8.4632(0.0000)^{* * *}$ & $-1.7284(0.958)$ & $-10.0664(0.0000)^{* * *}$ \\
\hline LnRen & $3.674933(1.0000)$ & $-5.6647(0.0001)^{* * *}$ & $-1.3506(0.9463)$ & $-5.6742(0.0000)^{* * *}$ \\
\hline LnAcess & $6.519073(1.0000)$ & $-6.1963(0.0000)^{* * *}$ & $-0.2492(0.7382)$ & $-8.8724(0.0003)^{* * *}$ \\
\hline LnCO2 & $-3.31456(0.6385)^{*}$ & $-10.7103(0.0000)^{* * *}$ & $-3.8383(0.0633)^{*}$ & $-12.4109(0.0000)^{* * *}$ \\
\hline LnCO2 $2^{2}$ & $-4.2134(0.0257)^{* *}$ & $-14.5280(0.0000)^{* * *}$ & $-5.2842(0.0134)^{* * *}$ & $-21.4244(0.0000)^{* * *}$ \\
\hline
\end{tabular}

Notes: The P-value is enclosed in the parentheses. All variables are logged, and significance is indicated as follows: ${ }^{*} * *$, $* *$ and $*$ for $1 \%, 5 \%$, and $10 \%$, respectively.

The panel unit root test in Table 2 revealed among others that only $\mathrm{CO}_{2}$ emission and its square is stationary at level with both IPS and Fisher based approaches while other variables are not stationary at level. We differenced the variables to achieve stationarity of the series. At first difference as in Table 2, all the series became stationary at 5 percent level of significance in both IPS and Fisher based approach. Since the variables are differenced to achieve stationarity, the study subjected the data to a cointegration test to ensure there exist long-run relationship among the series under investigation. To this end, Westerlund co-integration test was employed to determine if there is long-run relationship among the series.

Table-3. Westerlund cointegration test.

$\mathrm{H}_{0}$ : no cointegration with 54 series and 1 covariate

\begin{tabular}{c|c|c|c}
\hline Statistics & Value & Z-value & P-value \\
\hline $\mathrm{Gt}$ & -5.829 & -9.402 & 0.0000 \\
\hline $\mathrm{Ga}$ & -16.201 & -12.351 & 0.0000 \\
\hline $\mathrm{Pt}$ & -15.639 & -11.505 & 0.0000 \\
\hline $\mathrm{Pa}$ & -18.713 & -15.353 & 0.0000 \\
\hline
\end{tabular}

As expected, all the Westerlund result revealed the existence of long-run relationship among the series. As clearly seen in Table 3, all the series categories from $\mathrm{Gt}$ to $\mathrm{Pa}$ are all significant at 5 percent level of significance, an indication that the model is not just free from unit root, but the existing relationship holds in the long-run. The result from the models is presented in Table 4 using system GMM as the estimation techniques because of its superiority to other estimation techniques as discussed earlier. 


\begin{tabular}{|c|c|c|c|c|}
\hline Variables & (Model 1) & Model 2 & Model 3 & Model 4 \\
\hline & Coeff./P-value & Coeff./P-value & Coeff./P-value & Coeff./P-value \\
\hline Lny_1 & $-0.845(0.000)^{* * * *}$ & $-0.874(0.000) * * * *$ & $0.864(0.000)^{* * * *}$ & $-0.658(0.000)^{* * * *}$ \\
\hline$\Delta \mathrm{Lnk}$ & $0.353(0.000)^{* * *}$ & $0.382(0.000) * * *$ & $0.410(0.000)^{* * * *}$ & $0.311(0.000)^{* * * *}$ \\
\hline$\Delta \mathrm{LnL}$ & $0.034(0.000) * * *$ & $0.435(0.000)^{* * *}$ & O. $561(0.000)^{* * * *}$ & $0.519(0.001)^{* * * *}$ \\
\hline$\Delta$ LnAccess & $0.054(0.172)$ & $0.132(0.085)^{*}$ & $0.094(0.081)^{* *}$ & $0.228(0.036)^{* * *}$ \\
\hline$\Delta$ LnRen & $0.012(0.085)^{*}$ & $0.205(0.016) * *$ & $0.188(0.065)^{*}$ & $0.401(0.071)^{*}$ \\
\hline LnRen & - & $0.473(0.001)^{* * *}$ & $0.539(0.000)^{* * * *}$ & $0.613(0.000)^{* * * *}$ \\
\hline $\mathrm{LnCO} 2$ & - & - & $0.524(0.042)^{* *}$ & $0.342(0.012)^{* * *}$ \\
\hline $\mathrm{LnCO}_{2}{ }^{2}$ & - & - & - & $-0.038(0.011) * * *$ \\
\hline LnCO $2 *$ Ren & - & - & $-0.294(0.007) * * *$ & - \\
\hline Observations & 1026 & 1026 & 1026 & 1026 \\
\hline Number of c_id & 54 & 54 & 54 & 54 \\
\hline $\operatorname{AR}(2)$ & & 0.847 & 0.928 & 0.856 \\
\hline Hansen test & & 0.337 & 0.176 & 0.542 \\
\hline F-stat; P-value & $(0.000)^{* * * *}$ & $(0.000)^{* * *}$ & $(0.000)^{* * * *}$ & $(0.000)^{* * * *}$ \\
\hline
\end{tabular}

Notes: The P-value is enclosed in the parentheses. All variables are logged and significance is indicated as follows: ***, ** and $*$ fo $1 \%, 5 \%$ and $10 \%$ respectively.

The result from the first model in Table 4 revealed that renewable energy was not significant at 5 percent level of significance which conform to previous studies. Capital and labour however, meet the expected sign and is significant at 5 percent level. Specifically, a one percent increase in capital investment will increase economic growth by 35 percent, whereas a one percent increase in labour will increase economic growth by 3.4 percent. Access to electricity as a percentage of the population was seen insignificant at 5 percent level of significance. As we noted earlier, we introduced renewable energy consumption at level form to mitigate the effect of differencing the variables. As expected, the introduction improved the influence of other variables of income per capita positively and other variables previously not significant became significant. The impact of renewable energy consumption on income per capita which was at 1.2 percent earlier jumped to 47 percent.

To see the role of environmental sustainability in energy consumption and growth nexus, we introduced $\mathrm{CO}_{2}$ emission as a measure of environmental degradation. The argument is that rising renewable energy consumption will cause $\mathrm{CO}_{2}$ emission to fall. As such, its introduction in the model will improve the impact of renewable energy consumption on economic growth. But once $\mathrm{CO}_{2}$ is moderated with renewable energy, the relationship will turn negative. As revealed by our result in model $3, \mathrm{CO}_{2}$ emission have significant positive impact on economic growth. This is expected as countries with high industrial power tend to emit more $\mathrm{CO} 2$, but the impact turns negative when it was moderated with renewable energy consumption. One possible explanation is that renewable energy consumption has a negative relationship with $\mathrm{CO} 2$ emission. The positive impact of $\mathrm{CO} 2$ on the economy is more abstract than real. It can only be seen when interacting with renewable energy consumption to positively sign negative. It thus validates the fact that $\mathrm{CO}_{2}$ emission negatively impact economic growth in the long-run. This can easily be seen when we think of the fact that as countries remit more $\mathrm{CO}_{2}$ to drive economic growth through industrialization, it will get to the point that environmental degradation becomes a concern leading to disinvestment in industrialization via fossil fuels consumption so that economic growth will be impacted negatively.

This can be seen more clearly in model 4. There we introduced the square term of $\mathrm{CO}_{2}$ to check for the validity of Kuznet curve in $\mathrm{CO} 2$ emission and validate the fact that $\mathrm{CO}_{2}$ emission's positive impact on the economy is abstracted in the short-run. It was revealed that $\mathrm{CO}_{2}$ emission that initially positively impacted economic growth turned to a negative sign. This further justify our earlier assertion that as economies grow and emit more $\mathrm{CO}_{2}$, it will get to a point when environmental degradation becomes a concern and disinvestment in industrialization and in non-renewable energy will become the focus. As such, the growth part will be affected, and the earlier positive relationship will reverse.

Our models are free from serial correlation as revealed by Arellano-Bond test of higher-order serial correlation, the AR2 p-value are all greater than 0.5, as such we cannot reject the null hypothesis of serial correlation, thus our model is free from serial correlation. Hansen-Sargan test was also used to check for instrument validity and the result revealed that the instruments used are valid as the p-values are all above 1 percent level of significance.

\section{Conclusion}

One major conclusion from our study is that renewable energy consumption has significant positive impact on economic growth in developing countries, and that introduction of environmental degradation variables in our model strengthened that relationship. We however note that interacting renewable energy consumption with $\mathrm{CO}_{2}$ emission will turn the impact of $\mathrm{CO}_{2}$ emission on economic growth from positive to negative. We also conclude that as countries grow, they tend to disinvest in non-renewable energy driven-industrialization with the goal of reducing environmental degradation. The study for contemporary industrializing economies implies that the eventual long-run declines in economic growth can be mitigated by early investments in renewable energy infrastructure even as they drive towards necessary industrialization.

Our data reveal that electricity from renewable energy has been declining since the early 1970s while electricity from non-renewable energy has been rising, which is assumed not good for the environment. Secondly, the pace of industrialization might not be limited in the long-run if a country builds its industrialization technology around renewable energy. Future studies could focus on the degree to which mitigating the role of renewable energy consumption (such as emission taxes used to decrease degradation or renewable energy rebates) reduces growth in the long-run? Such a study will quantify the amount of growth rate losses that could be attributable to cleaner environment gains when nations reach the top of Kuznet's curve. 


\section{References}

Anastacio, J. A. R. (2017). Economic growth, $\mathrm{CO} 2$ emissions and electric consumption: Is there an environmental Kuznets curve? An empirical study for North America countries. International Journal of Energy Economics and Policy, 7(2), 65-71.

Apergis, N., \& Payne, J. E. (2010). Renewable energy consumption and economic growth: Evidence from a panel of OECD countries. Energy Policy, 38(1), 656-660. Available at: https://doi.org/10.1016/j.enpol.2009.09.002.

Arvind, C., \& Kaushik, G. (2017). Renewable energy technologies for sustainable development of energy efficient building. . Alexandria Engineering Journal, 30(1), 1-3.

Aslan, A. (2013). Energy consumption and GDP: The strong relationship in OECD countries. Journal Energy Sources, Part B: Economics, Planning, and Policy, 8(4), 339-345. Available at: https://doi.org/10.1080/15567240903502586.

Atems, B., \& Hotaling, C. (2018). The effect of renewable and nonrenewable electricity generation on economic growth. Energy Policy, 112 , 111-118. Available at: https://doi.org/10.1016/j.enpol.2017.10.015.

Bond, S., Hoeffler, A., \& Temple, J. (2001). GMM estimation of empirical growth models. Economica, 52(1), $234-246$.

Bozkurt, C., \& Destek, M. A. (2015). Renewable energy and sustainable development nexus in selected OECD countries. International Journal of Energy Economics and Policy, 5(2), 507-514.

Can, H., \& Korkmaz, Ö. (2018). The relationship between renewable energy consumption and economic growth: The case of Bulgaria. International Journal of Energy Sector Management, 13(3), 573-589.

Cole, M. A. (2004). Trade, the pollution haven hypothesis and the environmental Kuznets curve: Examining the linkages. Ecological Economics, 48(1), 71-81. Available at: https://doi.org/10.1016/j.ecolecon.2003.09.007.

Dinda, S. (2004). Environmental Kuznets curve hypothesis: A survey. Ecological Economics, 49(4), 431-455. Available at: https://doi.org/10.1016/j.ecolecon.2004.02.011.

Dogan, E., Sebri, M., \& Turkekul, B. (2016). Exploring the relationship between agricultural electricity consumption and output: New evidence from Turkish regional data. Energy Policy, 95, 370-377. Available at: https://doi.org/10.1016/j.enpol.2016.05.018.

Fotourehchi, Z. (2017). Clean energy consumption and economic growth: A case study for developing countries. International Journal of Energy Economics and Policy, 7(2), 61-64.

Grossman, G. M., \& Helpman, E. (1991). Innovation and growth in the global economy. Cambridge, MA: MIT Press.

Ibrahim, M. K., Sulaiman, C., \& Abdul-Rahim, A. (2019). Renewable energy consumption and economic growth nexus: A fresh evidence from West Africa. Energy Reports, 5, 384-392. Available at: https://doi.org/10.1016/j.egyr.2019.03.005.

IEA. (2015). Energy and climate change. World energy outlook special report. Retrieved from: https://www.iea.org/publications/freepublications/publication/WEO2015SpecialReportonEnergyandClimateChange.pdf

Im, K. S., Pesaran, M. H., \& Shin, Y. (2003). Testing for unit roots in heterogeneous panels. Journal of Econometrics, 115(1), 53-74. Available at: https://doi.org/10.1016/s0304-4076(03)00092-7.

Inglesi-Lotz, R. (2016). The impact of renewable energy consumption to economic growth: A panel data application. Energy Economics, 53, 58-63. Available at: https://doi.org/10.1016/j.eneco.2015.01.003.

Jebli, M. B., \& Youssef, S. B. (2015). The environmental Kuznets curve, economic growth, renewable and non-renewable energy, and trade in Tunisia. Renewable and Sustainable Energy Reviews, 47, 173-185. Available at: https://doi.org/10.1016/j.rser.2015.02.049.

Kisswani, K. M., Harraf, A., \& Kisswani, A. M. (2018). Revisiting the environmental Kuznets curve hypothesis: Evidence from the ASEAN-5 countries with structural breaks. Applied Economics, 3, 1-14.

Kuznet, S. (1955). Economic growth and income inequality. American Economic Review, 65(1), 1-28.

Lee, J. W. (2019). Long-run dynamics of renewable energy consumption on carbon emissions and economic growth in the European Union. International Journal of Sustainable Development \& World Ecology, 26(1), 69-78. Available at: 10.1080/13504509.2018.1492998.

Marinaș, M. C., Dinu, M., Socol, A. G., \& Socol, C. (2018). Renewable energy consumption and economic growth. Causality relationship in Central and Eastern European countries. PLOS One, 13(10), 1-8. Available at: https://doi.org/10.1371/journal.pone.0202951.

Oladeji, J. (2014). Renewable energy as a sure solution to Nigeria's perennial energy problems-an overview. Researcher, 6(4), 45-50.

Stern, D. I. (201 1). The role of energy in economic growth. International Energy and Poverty, 1219(1), 35-47.

Tafti, M. A. D., \& Mottaghitalab, A. (2017). Renewable energy consumption and its impact on economic growth of OPEC members. International Journal of Chemoinformatics and Chemical Engineering, 6(1), 39-47. Available at: 10.4018/ijcce.2017010103

Tonuchi, E. J. (2019). Investigating renewable energy potentials in solving energy crisis in Niger Delta riverine communities, Nigeria. International Journal of Research in Electronics and Computer Engineering, 7(3), 905-915.

Vaselbehagh, M., Karkhanechi, H., Takagi, R., \& Matsuyama, H. (2017). Biofouling phenomena on anion exchange membranes under the reverse electrodialysis process. Journal of Membrane Science, 530, 232-239. Available at: https://doi.org/10.1016/j.memsci.2017.02.036.

Zhou, W., Yang, H., \& Lu, L. (2012). A novel optimization sizing model for hybrid solar-wind power generation system. Solar Energy, 81(1), $76-84$. 